\title{
ANALISIS PENGARUH KEPUASAN TERHADAP LOYALITAS KONSUMEN SMARTPHONE SAMSUNG MENGGUNAKAN METODE PARTIAL LEAST SQUARE PADA MAHASISWA UNIVERSITAS DIPONEGORO SEMARANG
}

\author{
Jeffe rio Gus ti Putratama ${ }^{1}$, Alan Prahutama ${ }^{2}$, Suparti ${ }^{3}$ \\ 1, 2, 3 Departemen Statistika, Fakultas Sains dan Matematika, Universitas Diponegoro \\ email: jefferiogusti@students.undip.ac.id
}

\begin{abstract}
Smartphones are one of the electronic devices that are capable of experiencing fairly rapid development. The existence of this Smartphone is considered to be the most important item for used everyday. Samsung is one of the most popular smartphone brand in Indonesia. Based on data from the website of the Statcounter survey institute, it was found that the Samsung market share in Indonesia until August 2020 was in the top position, namely $24.19 \%$. Samsung continues to make various innovations in order to continue to dominate the top of the smartphone sales segment. In addition, to provide consumer's satisfic ation so that consumer's loyalty to the Samsung brand will be maintained. The purpose of this study is to make measurement models and structural models, as well as to test the relationship of customer satisfac tion to consumer loyalty of Samsung smartphones using the SEM - PLS (Partial Least Square) method. This research was conducted on Diponegoro University students who have purchased and used a Samsung smartphone. This research was conducted on Diponegoro University students who have purchased and used a Samsung smartphone. This research has produced 4 latent variables with 18 measurement models and 2 structural models. Based on the 2 structural models formed, the result shows that the $\mathrm{R}^{2}$ value in the customer satisfaction model is 0.670 . This indicates that the variable customer satisfaction can be explained by the variable product quality and price by $67 \%$. Meanwhile, in the consumer loyalty model, the $\mathrm{R}^{2}$ value is 0.478 . This indicates that the consumer loyalty variable can be explained by the consumer satisfaction variable of $47.8 \%$.
\end{abstract}

Keywords: Samsung Smartphone, Consumer's Satisfaction, Consumer's Loyalty, Partial Least Square.

\section{PENDAHULUAN}

Samsung merupakan salah satu merek smartphone yang paling banyak diminati di Indonesia. Berdasarkan data dari website lembaga survei statcounter, diperoleh bahwa market share Samung di Indonesia hingga agustus 2020 menempati posisi teratas yakni sebesar 24,19\%. Samsung terus melakukan berbagai inovasi agar terus merajai puncak segmen penjualan smartphone. Tujuan melakukan inovasi ini yaitu supaya smartphone Samsung juga dapat bersaing dari kompetitor-kompetitornya. Selain itu juga untuk memberikan kepuasan terhadap konsumen sehingga loyalitas konsumen terhadap merek Samsung akan tetap terjaga.

Maka dari itu perlu dilakukan sebuah penelitian mengenai hubungan kepuasan konsumen terhadap loyalitas konsumen smartphone Samsung. Penelitian ini dilakukan dengan menggunakan metode Partial Least Square yang bertujuan untuk menguji hubungan dari kepuasan konsumen terhadap loyalitas konsumen smartphone Samsung. Dalam penelitian ini Kepuasan Konsumen dan Loyalitas Konsumen sebagai variabel laten, dimana Kepuasan Konsumen diukur oleh variabel Kualitas Produk, Harga, Citra Merek, serta Promosi.

\section{TINJAUAN PUSTAKA}

\subsection{Perkembangan Smartphone Samsung di Indonesia}

Setiap tahun smartphone merek Samsung selalu mengeluarkan produk-produk baru mereka sehingga selalu minat pembeli. Menurut Hieronimus Patardo (2019), Samsung masih 
menguasai pangsa pasar smartphone di Indonesia. Lembaga riset GfK (Growthfor Knowledge) menyebut, pangsa pasar Samsung di Indonesia masih unggul dengan porsi sebesar 42 persen. Pihak Samsung terus melakukan inovasi guna meningkatkan kepuasan pelanggan. Kepuasan konsumen merupakan ungkapan perasaan seorang yang digambarkan setelah membandingkan apa yang diharapkan dengan apa yang ditawarkan perusahaan (Sunarti, 2016). Dengan adanya kepuasan konsumen, pihak samsung berharap agar loyalitas konsumen dapat selalu terjaga. Menurut Oliver yang dikutip dalam Rath Hurriyati (2005), loyalitas pelanggan adalah komitmen pelanggan bertahan secara mendalam untuk berlangganan kembali atau melakukan pembelian ulang merek/jasa terpilih secara konsisten di masa yang akan datang, meskipun pengaruh situasi dan usaha-usaha pemasaran mempunyai potensi untuk perubahan perilaku.

Ada banyak faktor yang menentukan kepuasan konsumen terhadap suatu produk, yang pertama adalah kualitas produk. Menurut Kotler dan Amstrong dalam Gaol et al. (2012), kualitas produk adalah kemampuan sebuah produk dalam memperagakan fungsiya, hal ini termasuk keseluruhan durabilitas, reliabilitas, ketepatan, kemudahan pengoperasian, dan reparasi produk, juga atribut produk lainnya. Faktor yang kedua adalah Harga. Menurut Sondakh (2014), Produk yang mempunyai kualitas yang sama tetapi menetapkan harga yang relatif murah akan memberikan nilai yang lebih tinggi kepada pelanggannya. Ketiga adalah faktor citra merek. Citra Merek menurut Sondakh (2014) merupakan representasi dari keseluruhan persepsi terhadap merek dan bentuk dari informasi dan pengalaman masa lalu terhadap merek itu. Kemudian faktor promosi juga dapat menentukan kepuasan konsumen. Menurut Tjiptono dalam Trisnawan (2014), "Promosi adalah suatu bentuk komunikasi pemasaran dimana aktivitas pemasaran berusaha menyebarkan informasi, mempengaruhi atau membujuk, mengingatkan pasar sasaran atas perusahaan dan produknya agar bersedia menerima, membeli, dan loyal pada produk yang ditawarkan perusahaan yang bersangkutan".

\subsection{Skala Pengukuran pada Variabel}

Skala Pengukuran adalah kategori respon ataupun item yang menunjukkan ukuran dari suatu variabel, baik kualitatif maupun kuantitatif. Menentukan skala (scale) pengukuran terhadap indikator-indikator dari variabel disebut scalling. Tipe skala pengukuran ada 4, diantaranya yaitu skala nominal, ordinal, interval, dan rasio.

\subsection{Uji Validitas dan Reliabilitas Kuisioner}

\subsubsection{Uji Validitas}

Menurut Sujarweni dan Endrayanto (2012), validitas digunakan untuk mengetahui kelayakan butir-butir pernyataan $(\rho)$ dalam mendefinisikan suatu variabel. Hipotesis:

$\mathrm{H}_{0}: \rho=0$ (item pernyataan tidak valid)

$\mathrm{H}_{1}: \rho \neq 0$ (item pernyataan valid)

Statistik Uji: $\quad r=\frac{n \sum_{i=1}^{n} X_{i} Y_{i}-\sum_{i=1}^{n} X_{i} \sum_{i=1}^{n} Y_{i}}{\sqrt{\left[n \sum_{i=1}^{n} X_{i}^{2}-\left(\sum_{i=1}^{n} X_{i}\right)^{2}\right]}\left[n \sum_{i=1}^{n} Y_{i}^{2}-\left(\sum_{i=1}^{n} Y_{i}\right)^{2}\right]}$

$r$ untuk setiap butir pernyataan $(\rho)$

Keterangan:

$\mathrm{X}$ : skor item pernyataan/variabel indikator

$\mathrm{Y}$ : Total skor item pertanyaan/variabel indikator n: ukuran sampel

Kriteria uji: $\mathrm{H}_{0}$ ditolak jika nilai $\mathrm{r}>\mathrm{r}_{(\alpha ; \mathrm{df})}$ dengan $\mathrm{df}=\mathrm{n}-2$, sehingga kuesioner tersebut dinyatakan valid artinya suatu butir pernyataan/variabel indikator memiliki kontribusi terhadap keseluruhan pernyataan/variabel indikator (Sujarweni dan Endrayanto, 2012). 


\subsubsection{Uji Reliabilitas}

Reliabilitas menunjukkan akurasi, konsistensi, dan ketepatan suatu alat ukur dalam melakukan pengukuran (Hartono, 2008). Teknik perhitungan uji reliabilitas yang digunakan adalah Cronbach Alpha yang ditulis dengan rumus sebagai berikut:

$$
\text { Alpha Cronbach }=\frac{k}{k-1}\left(1-\frac{\sum_{i=1}^{k} S_{i}^{2}}{S_{\text {total }}^{2}}\right)
$$

Keterangan: $\quad S_{\text {total }}^{2}: \frac{\sum_{i=1}^{n} X_{i}^{2}-\frac{\left(\sum_{i=1}^{n} x_{i}\right)^{2}}{n}}{n}$ dimana $X_{i}:$ skor item pertanyaan, $S_{\text {total }}^{2}$ : varian total item pertanyaan,

k: banyaknya item pernyataan n: ukuran sampel

$\sum_{i=1}^{k} S_{i}^{2} \quad$ jumlah varian dari item pernyataan

Kriteria uji: Suatu instrumen dikatakan reliabel jika nilai Cronbach Alpha > 0,60 (Sujarweni dan Endrayanto, 2012).

\subsection{Structural Equation Model}

Menurut Wright dalam Abdillah dan Jogiyanto (2015), Structural Equation Model (SEM) adalah suatu teknik statistika untuk menguji dan mengestimasi hubungan kausal dengan mengintegrasi analisis faktor dan analisis jalur. Salah satu keunggulan SEM adalah kemampuan mengukur variabel laten yang tidak secara langsung diukur tetapi melalui estimasi indikator atau parameternya.

\subsection{Partial Least Square (PLS)}

Partial Least Square (PLS) pertama kali dikembangkan oleh Herman Wold, sebagai metode umum untuk mengestimasi model jalur yang menggunakan konstruk laten dengan multiple indikator. Sebagai alat model prediksi, PLS mendefinisikan variabel laten sebagai linear agregat (selisih) dari indikatornya.

\subsubsection{Variabel Laten dengan Indikator Reflektif dan Indikator Formatif}

Variabel laten adalah variabel yang tidak dapat diobservasi secara langsung sehingga harus memiliki defenisi operasional dengan menggunakan beberapa item atau indikator untuk merepresentasi variabel tersebut. Model indikator reflektif mengasumsikan bahwa kovarian di antara pengukuran dijelaskan oleh varian yang merupakan manifestasi dari konstruk latennya. Model indikator formatif mengasumsikan bahwa pengukuran saling terikat mempengaruhi konstruk latennya.

\subsubsection{Spesifikasi Model PLS}

Menurut (Ghozali, 2011), Model spesifikasi PLS dalam analisis jalur terdiri atas tiga tipe hubungan, yaitu Inner model, outer model, dan weight relation.

1. Inner model

menunjukkan spesifikasi hubungan kausal antar variabel laten (model struktural).

2. Outer model

Menunjukkan spesifikasi hubungan antara indikator atau parameter yang diestimasi dengan variabel latennya (model pengukuran).

3. Weight relation

Menunjukkan hubungan nilai varian antar indikator dengan variabel latennya.

\subsubsection{Algoritma PLS}

Algoritma terdiri dari tiga tahap, yaitu:

\section{Tahap 1}

Menurut Ghozali dan Latan (2014), komponen skor estimasi untuk setiap variabel laten diperoleh dengan 2 (dua) cara yaitu, melalui outside approximation untuk model pengukuran dan inside approximation untuk model struktural. 


\section{Tahap 1.1 Outside Approximation}

Tahap untuk mengestimasi setiap variabel laten sebagai kombinasi linier $\xi_{\mathrm{j}}$ (untuk variabel eksogen) dari variabel indikator $\mathrm{x}_{\mathrm{jk}}$ dan $\eta_{\mathrm{j}}$ (untuk variabel endogen) dari variabel indikator $\mathrm{y}_{\mathrm{jk}}$ dengan menghitung pembobot melalui proses iterasi. Persamaan untuk menghitung skor variabel laten:

$$
\begin{aligned}
& \left.\xi_{\mathrm{j}}=\sum_{\mathrm{k}=1}^{\mathrm{k}_{\mathrm{i}}} \widetilde{\mathrm{w}}_{\mathrm{jk}} \mathrm{x}_{\mathrm{jk}} \text { (Variabel Laten Eksogen }\right) \\
& \left.\eta_{\mathrm{j}}=\sum_{\mathrm{k}=1}^{\mathrm{k}_{\mathrm{i}}} \widetilde{\mathrm{w}}_{\mathrm{jk}} \mathrm{y}_{\mathrm{jk}} \text { (Variabel Laten Endogen }\right)
\end{aligned}
$$

dengan $\widetilde{\mathrm{w}}_{\mathrm{jk}}$ adalah outer weight. Menurut Trujillo (2013) untuk memudahkan iterasi maka semua pembobot awal diberi nilai sama dengan $1\left(\widetilde{\mathrm{w}}_{\mathrm{jk}}=1\right)$.

\section{Tahap 1.2 Inside Approximation}

a. Centroid Scheme

Bobot inner model $\mathrm{e}_{\mathrm{ij}}$ merupakan korelasi tanda (sign correaltion) antara $\mathrm{Y}_{\mathrm{i}}$ dan $\mathrm{Y}_{\mathrm{j}}$.

b. Factor Scheme

Bobot inner model $\left(e_{i j}\right)$ merupakan korelasi antara $Y_{j}$ dan $Y_{i}$

c. Path Scheme

inner weight adalah koefisien regresi dari $\mathrm{Y}_{\mathrm{i}}$ dalam regresi berganda terhadap $\mathrm{Y}_{\mathrm{j}}$.

\section{Tahap 1.3 Updating Outer Weight}

Pada hubungan reflektif setiap outer weight (penimbang) $w_{j k}$ adalah koefisien regresi sederhana dari $Z_{j}$ dan $Y_{j k}$ serta $Z_{j}$ dan $X_{j k}$. Dengan $X_{j k}$ adalah hasil regresi dari outer weight $\left(w_{j k}\right)$ dengan variabel eksogen $\mathrm{Z}_{\mathrm{j}}$ dan $\mathrm{Y}_{\mathrm{jk}}$ adalah hasil regresi dari outer weight $\left(w_{j k}\right)$ dengan variabel endogen $\mathrm{Z}_{\mathrm{j}}$.

$$
\begin{array}{ll}
\mathrm{x}_{\mathrm{jk}}=\mathrm{w}_{\mathrm{jk}} Z_{\mathrm{j}}+\delta_{\mathrm{jk}} & \text { (Refleksif Eksogen) } \\
\mathrm{y}_{\mathrm{jk}}=\mathrm{w}_{\mathrm{jk}} Z_{\mathrm{j}}+\varepsilon_{\mathrm{jk}} & \text { (Refleksif Endogen) }
\end{array}
$$

Estimasi model reflektif diperoleh dengan metode least square dengan cara meminimumkan jumlah kuadrat eror $\left(\delta_{j k}\right.$ atau $\left.\varepsilon_{j k}\right)$.

Jumlah kuadrat $\delta_{j k}$ diturunkan terhadap $\mathrm{w}_{j k}$ hingga diperoleh:

$$
\widehat{w}_{j k}=\frac{\operatorname{Cov}\left(\mathrm{x}_{j k}, Z_{j}\right)}{\operatorname{var}\left(Z_{j}\right)}
$$

(Riyanti et al., 2016)

Hal ini sejalan dengan indikator reflektif terhadap variabel endogen yang memiliki persamaan:

$$
\begin{aligned}
& \mathrm{y}_{\mathrm{jk}}=\mathrm{w}_{\mathrm{jk}} \mathrm{Z}_{\mathrm{j}}+\varepsilon_{\mathrm{jk}} \\
& \widehat{w}_{j k}=\frac{\operatorname{Cov}\left(\mathrm{y}_{j k}, Z_{j}\right)}{\operatorname{var}\left(Z_{j}\right)}
\end{aligned}
$$

\section{Tahap 1.4 Pemeriksaan Konvergensi}

Berdasarkan Ghozali dan Latan (2014) menyarankan batasan $\left|\widetilde{w}_{j k}^{s-1}-\widetilde{w}_{j k}^{s}\right|<$ $10^{-5}$ sebagai batas konvergensi. Jika telah konvergen, maka didapat nilai dugaan akhir variabel laten. $\quad X_{j}=\sum_{k=1}^{k_{i}} \widetilde{w}_{j k}^{n e w} X_{j k}$ (Variabel Eksogen)

\section{Tahap 2}

$$
\begin{aligned}
X_{j} & =\sum_{k=1}^{k_{i}} \widetilde{w}_{j k}^{n e w} X_{j k}(\text { Variabel Eksogen }) \\
Y_{j} & =\sum_{k=1}^{k_{i}} \widetilde{w}_{j k}^{n e w} Y_{j k}(\text { Variabel Endogen })
\end{aligned}
$$

Tahap kedua menduga estimasi koefisien jalur $\widehat{\beta_{J l}}=\beta_{j i}$ untuk setiap inner model. Untuk model struktural, koefisien jalur diduga dengan ordinary least square pada regresi berganda $\mathrm{Y}_{\mathrm{j}}$ dan $Y_{\mathrm{i}}$ yang bersesuaian. $\quad \boldsymbol{Y}_{\boldsymbol{j}}=\sum_{\boldsymbol{i} \leftrightarrow \boldsymbol{j}} \widehat{\boldsymbol{\beta}_{\boldsymbol{J} \boldsymbol{}}} \boldsymbol{Y}_{\boldsymbol{i}}$

$$
\text { Sehingga, } \widehat{\boldsymbol{\beta}}_{\boldsymbol{\jmath} \boldsymbol{\imath}}=\left(\boldsymbol{Y}_{\boldsymbol{i}}{ }^{\prime} \boldsymbol{Y}_{\boldsymbol{i}}\right)^{-\mathbf{1}} \boldsymbol{Y}_{\boldsymbol{i}} \boldsymbol{Y}_{\boldsymbol{j}}
$$




\section{Tahap 3}

Menurut Trijullo dalam Nataila (2017), pada tahap ketiga algoritma ini terdiri dari menghitung koefisien loading. Koefisien loading diperoleh dengan menghitung korelasi antara variabel laten dengan masing-masing indikatornya.

\subsubsection{Evaluasi Model PLS}

$$
\begin{gathered}
\hat{\lambda}_{j k}=\operatorname{cor}\left(X_{j k}, X_{j}\right) \text { (Variabel Eksogen) } \\
\hat{\lambda}_{j k}=\operatorname{cor}\left(Y_{j k}, Y_{j}\right) \text { (Variabel Endogen) }
\end{gathered}
$$

\section{a. Evaluasi model Pengukuran}

1) Indicator Reliability

Ukuran yang digunakan untuk mengukur reliabilitas indikator tersebut yaitu dengan melihat nilai koefisien hubungan setiap indikator terhadap variabel laten. Nilai uji yang digunakan untuk menilai bahwa koefisien hubungan setiap indikator terhadap variabel laten sudah reliabel, yaitu nilai koefisien tersebut harus lebih besar dari 0,6.

2) Composite Reliability $\left(\rho_{c}\right)$

Nilai Composite Reliability $\left(\rho_{c}\right)$ yang tinggi menunjukkan konsistensi yang tinggi dari blok indikator dalam mengukur varaiabel laten. Direkomendasikan nilai Composite Reliability $\left(\rho_{c}\right)$ lebih besar dari 0,7 (Abdillah \& Jogiyanto, 2015).

Composite Reliability $\left(\rho_{c}\right)$ dihitung dengan rumus sebagai berikut:

$$
\rho_{c}=\frac{\left(\sum_{k} \lambda_{j k}\right)^{2}}{\left(\sum_{k} \lambda_{j k}\right)^{2}+\sum_{k} \operatorname{var}\left(\varepsilon_{j k}\right)}
$$

3) Convergent Validity

Cara untuk menguji kevalidan dari konvergensi outer weight adalah dengan melihat nilai Average Variance Extracted (AVE) yang harus lebih besar dari 0.50 . Dengan nilai AVE diperoleh dari rumus:

$$
A V E=\frac{\sum_{k} \lambda^{2}{ }_{j k}}{\sum_{k} \lambda^{2}{ }_{j k}+\sum_{k} \operatorname{var}\left(\varepsilon_{j k}\right)}
$$

4) Discrimininant Validity

Uji validitas diskriminan (Discrimininant Validity) dapat dilihat dari nilai crossloading antara indikator dan variabel latennya. Suatu indikator dinyatakan valid jika pada skor loading terlihat bahwa masing-masing indikator akan memiliki skor loading yang lebih tinggi terhadap variabel konstruknya, dibandingkan terhadap variabel konstruk yang lainnya.

b. Evaluasi Model Struktural

1) Koefisien Determinasi $\left(R^{2}\right)$

Nilai $\mathrm{R}^{2}$ menunjukkan seberapa besar keragaman pada variabel endogen yang mampu dijelaskan oleh variabel eksogen.

2) Predictive Relevance $\left(\mathrm{Q}^{2}\right)$

Predictive Relevance $\left(\mathrm{Q}^{2}\right)$ digunakan untuk validasi kemampuan prediksi model. Apabila nilai $\mathrm{Q}^{2}$ lebih dari nol, maka dikatakan bahwa model struktural memiliki prediksi yang relevan. Sebaliknya jika nilai $\mathrm{Q}^{2}$ kurang dari nol menunjukkan

\begin{tabular}{|c|c|c|}
\hline No & Model Fit & Kriteria Fit \\
\hline 1 & $\begin{array}{l}\text { SRMR (Standardized Root } \\
\text { Mean Square Residual) }\end{array}$ & baik jika nilai SRMR \\
\hline 2 & NFI (Norm Fit Index) & Model dikatakan baik jika nilai \\
\hline
\end{tabular}
bahwa model kurang memiliki prediksi yang relevan (Ghozali dan Latan, 2014).

3) Model Fit (Kecocokan Model)

Tabel 1. Kriteria Model Fit 


\section{METODOLOGI PENELITIAN}

\subsection{Jenis dan sumber data}

Penelitian menggunakan data primer yang diperoleh dari kuesioner. Ukuran Sampel dalam penelitian ini adalah 119 responden. PLS tidak memerlukan ukuran sampel yang besar. Oleh karena itu ukuran sampel dalam penelitian ini memenuhi syarat dengan metode PLS. Teknik pengambilan sampel yang digunakan adalah non-probability sampling yaitu teknik judgemental sampling. Dimana kriteria responden dari penelitian ini adalah Mahasiswa Universitas Diponegoro yang telah membeli dan menggunakan merek smartphone Samsung.

\subsection{Model Teoritis dan Hipotesis Penelitian}

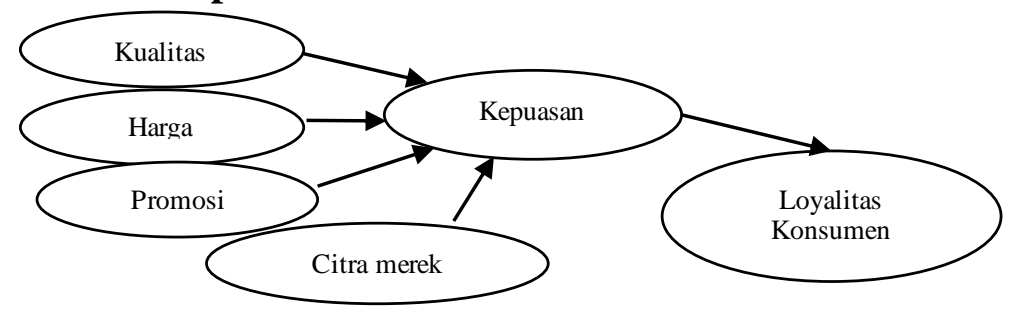

hubungan kepuasan konsumen terhadap loyalitas konsumen merek Samsung dapat dirumuskan beberapa hipotesis sebagai berikut:

$\mathrm{H}_{1}$ : Kualitas Produk smartphone Samsung memiliki pengaruh terhadap Kepuasan konsumen.

$\mathrm{H}_{2}$ : Harga smartphone Samsung memiliki pengaruh terhadap Kepuasan konsumen.

$\mathrm{H}_{3}$ : Promosi smartphone Samsung memiliki pengaruh terhadap Kepuasan konsumen.

$\mathrm{H}_{4}$ : Citra merek smartphone Samsung memiliki pengaruh terhadap Kepuasan konsumen.

$\mathrm{H}_{5}$ : Kepuasan konsumen memiliki pengaruh terhadap Loyalitas konsumen smartphone Samsung.

\section{HASIL DAN PEMBAHASAN}

\subsection{Uji validitas}

Tabel 2. Uji validitas

\begin{tabular}{cccc}
\hline Variabel & Indikator & Nilai $\mathrm{r}$ & Keterangan \\
\hline \multirow{5}{*}{$\xi_{1}$} & $\mathrm{X}_{11}$ & 0,635 & Valid \\
& $\mathrm{X}_{12}$ & 0,837 & Valid \\
& $\mathrm{X}_{13}$ & 0,862 & Valid \\
& $\mathrm{X}_{14}$ & 0,708 & Valid \\
& $\mathrm{X}_{15}$ & 0,838 & Valid \\
\hline \multirow{5}{*}{$\xi_{2}$} & $\mathrm{X}_{21}$ & 0,846 & Valid \\
& $\mathrm{X}_{22}$ & 0,893 & Valid \\
& $\mathrm{X}_{23}$ & 0,907 & Valid \\
& $\mathrm{X}_{24}$ & 0,816 & Valid \\
\hline \multirow{5}{*}{$\xi_{3}$} & $\mathrm{X}_{31}$ & 0,842 & Valid \\
& $\mathrm{X}_{32}$ & 0,674 & Valid \\
& $\mathrm{X}_{33}$ & 0,864 & Valid \\
& $\mathrm{X}_{34}$ & 0,845 & Valid \\
\hline \multirow{3}{*}{$\xi_{4}$} & $\mathrm{X}_{41}$ & 0,804 & Valid \\
& $\mathrm{X}_{42}$ & 0,734 & Valid \\
& $\mathrm{X}_{43}$ & 0,632 & Valid \\
& $\mathrm{X}_{44}$ & 0,788 & Valid \\
\hline \multirow{5}{*}{$\eta_{1}$} & $\mathrm{Y}_{11}$ & 0,877 & Valid \\
& $\mathrm{Y}_{12}$ & 0,882 & Valid \\
& $\mathrm{Y}_{13}$ & 0,891 & Valid \\
& $\mathrm{Y}_{14}$ & 0,925 & Valid \\
& $\mathrm{Y}_{15}$ & 0,868 & Valid \\
\hline
\end{tabular}




\begin{tabular}{llll}
\hline & $\mathrm{Y}_{21}$ & 0,834 & Valid \\
$\eta_{2}$ & $\mathrm{Y}_{22}$ & 0,904 & Valid \\
& $\mathrm{Y}_{23}$ & 0,907 & Valid \\
& $\mathrm{Y}_{24}$ & 0,805 & Valid \\
\hline
\end{tabular}

\subsection{Uji Reliabilitas}

Tabel 3. Uji Reliabilitas

\begin{tabular}{lcc}
\hline \multicolumn{1}{c}{ Variabel } & Cronbach Alpha & Keterangan \\
\hline Kualitas Produk $\left(\xi_{1}\right)$ & 0,738 & Reliabel \\
Harga $\left(\xi_{2}\right)$ & 0,890 & Reliabel \\
Promosi $\left(\xi_{3}\right)$ & 0,933 & Reliabel \\
Citra merek $\left(\xi_{4}\right)$ & 0,835 & Reliabel \\
Kepuasan Konsumen $\left(\eta_{1}\right)$ & 0,885 & Reliabel \\
Loyalitas Konsumen $\left(\eta_{2}\right)$ & 0,823 & Reliabel \\
\hline
\end{tabular}

\subsection{Analis is Model Penelitian}

Pada Model awal masih ada variabel yang tidak berpengaruh signifikan maka model harus dikonstruksi ulang dengan melakukan trimming yaitu menghapus variabel yang tidak memenuhi kriteria validasi model struktural. Setelah dilakukan evaluasi model dan uji hipotesis pada model awal, diperoleh bahwa variabel Citra merek dan Promosi tidak memiliki pengaruh yang signifikan. Sehingga, Variabel yang akan dihapus untuk membentuk model baru adalah variabel Citra Merek dan Promosi. Maka, didapatkan model akhir untuk 18 model pengukuran dengan indikator X11, X12, X13, X14, X15, X21, X22, X23, X24, Y11, Y12, Y13, Y14, Y15, Y21, Y22, Y23, Y24. Dengan model struktural yaitu Kepuasan Konsumen $\left(\eta_{1}\right)$ yang dijelaskan oleh variabel Kualitas Produk $\left(\xi_{1}\right)$ dan Harga $\left(\xi_{2}\right)$ serta variabel Loyalitas Konsumen $\left(\eta_{2}\right)$ yang dijelaskan oleh Kepuasan Konsumen $\left(\eta_{1}\right)$.

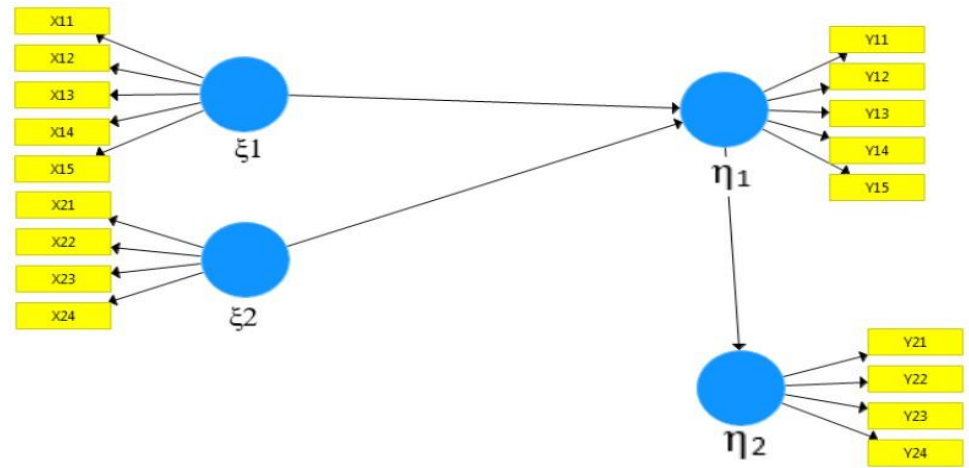

Gambar 2. Diagram Jalur Model Akhir PLS

\subsubsection{Estimasi parameter}

Tahap pertama adalah estimasi untuk setiap variabel laten sebagai kombinasi linier dari indikatornya, dengan menghitung pembobot melalui proses iterasi.

Tahap kedua adalah estimasi non-iteratif untuk menghasilkan koefisien model pengukuran (outer loadings).

Tabel 4. Nilai Outer Loading

\begin{tabular}{lll}
\hline Variabe & Outer Loading & Nilai Outer Loading \\
\hline Kualitas & $\lambda_{11}$ & 0,604 \\
Produk & $\lambda_{12}$ & 0,849 \\
& $\lambda_{13}$ & 0,874 \\
& $\lambda_{14}$ & 0,688 \\
& $\lambda_{15}$ & 0,853 \\
\hline Harga & $\lambda_{21}$ & 0,887 \\
& $\lambda_{22}$ & 0,832
\end{tabular}




\begin{tabular}{lll} 
& $\lambda_{23}$ & 0,854 \\
& $\lambda_{24}$ & 0,880 \\
\hline Kepuasan & $\lambda_{11}$ & 0,878 \\
Konsumen & $\lambda_{12}$ & 0,884 \\
& $\lambda_{13}$ & 0,891 \\
& $\lambda_{14}$ & 0,925 \\
& $\lambda_{15}$ & 0,865 \\
\hline Loyalitas & $\lambda_{21}$ & 0,844 \\
Konsumen & $\lambda_{22}$ & 0,924 \\
& $\lambda_{23}$ & 0,911 \\
& $\lambda_{24}$ & 0,767 \\
\hline
\end{tabular}

Tahap ketiga adalah estimasi non-iteratif untuk menghasilkan koefisien model jalur struktural Tabel 5. Koefisien Jalur

\begin{tabular}{lll}
\hline Pengaruh Variabel & Koefisien Jalur & Estimasi Koefisien Jalur \\
\hline Kualitas Produk $\rightarrow$ Kepuasan & $\gamma_{11}$ & 0,519 \\
Konsumen & $\gamma_{12}$ & 0,428 \\
Harga $\rightarrow$ Kepuasan Konsumen & $\beta_{12}$ & 0,695 \\
Kepuasan Konsumen $\rightarrow$ Loyalitas & &
\end{tabular}

\subsubsection{Evaluasi model pengukuran}

\section{a. Reliabilitas indikator}

Dilihat dari nilai Outer Loading Model II dapat disimpulkan bahwa semua koefisien hubungan indikator telah memenuhi uji reliabilitas indikator dikarenakan nilai outer loading lebih dari 0,6.

b. Reliabilitas komposit

Tabel 6. Composite Reliability

\begin{tabular}{lc}
\hline Variabel & Composite Reliability \\
\hline Kualitas Produk & 0,885 \\
Harga & 0,921 \\
Kepuasan Konsumen & 0,949 \\
Loyalitas Konsumen & 0,921 \\
\hline
\end{tabular}

Dapat disimpulkan bahwa nilai composite reliability pada semua variabel bernilai lebih dari 0,6. Hal ini mengindikasikan bahwa masing-masing variabel indikator memiliki konsistensi yang tinggi dalam mengukur variabel laten.

c. Validitas konvergensi

Berdasarkan Tabel 22 diperoleh informasi bahwa nilai AVE pada semua variabel memiliki nilai lebih besar dari 0,5. Hal ini mengindikasikan bahwa outer weight setiap indikator variabel Kualitas Produk, Harga, Citra merek, Promosi, Kepuasan Konsumen, Loyalitas Konsumen yang sudah konvergen adalah valid.

Tabel 7. Covergent validity

\begin{tabular}{lc}
\multicolumn{2}{c}{ Tabel 7. Covergent validity } \\
\hline Variabel & $\boldsymbol{A} \boldsymbol{V E}$ \\
\hline Kualitas Produk & 0,610 \\
Harga & 0,746 \\
Kepuasan Konsumen & 0,790 \\
Loyalitas Konsumen & 0,746 \\
\hline
\end{tabular}

d. Validitas diskriminan

Diperoleh semua nilai korelasi antar indikator dengan variabel latennya paling tinggi dibandingkan pada variabel lain. Hal ini mengindikas ikan bahwa beberapa variabel laten mampu memprediksi indikatornya lebih baik dibandingkan variabel laten lainnya. 
Tabel 8. Cross Loading

\begin{tabular}{lcccc}
\hline HARGA & $\begin{array}{c}\text { KEPUASAN } \\
\text { KONSUMEN }\end{array}$ & $\begin{array}{c}\text { KUALITAS } \\
\text { PRODUK }\end{array}$ & $\begin{array}{c}\text { LOYALITAS } \\
\text { KONSUMEN }\end{array}$ \\
\hline X11 & 0.206 & 0.402 & $\mathbf{0 . 6 0 4}$ & 0.290 \\
X12 & 0.490 & 0.667 & $\mathbf{0 . 8 4 9}$ & 0.456 \\
X13 & 0.430 & 0.602 & $\mathbf{0 . 8 7 4}$ & 0.384 \\
X14 & 0.332 & 0.442 & $\mathbf{0 . 6 8 8}$ & 0.229 \\
X15 & 0.435 & 0.682 & $\mathbf{0 . 8 5 3}$ & 0.402 \\
X21 & $\mathbf{0 . 8 8 7}$ & 0.644 & 0.512 & 0.397 \\
X22 & $\mathbf{0 . 8 3 2}$ & 0.434 & 0.246 & 0.310 \\
X23 & $\mathbf{0 . 8 5 4}$ & 0.462 & 0.273 & 0.395 \\
X24 & $\mathbf{0 . 8 8 0}$ & 0.737 & 0.579 & 0.506 \\
Y11 & 0.568 & $\mathbf{0 . 8 7 4}$ & 0.707 & 0.559 \\
Y12 & 0.751 & $\mathbf{0 . 8 7 9}$ & 0.602 & 0.567 \\
Y13 & 0.590 & $\mathbf{0 . 8 9 4}$ & 0.605 & 0.685 \\
Y14 & 0.575 & $\mathbf{0 . 9 2 8}$ & 0.688 & 0.669 \\
Y15 & 0.576 & $\mathbf{0 . 8 6 7}$ & 0.659 & 0.604 \\
Y21 & 0.408 & 0.583 & 0.442 & $\mathbf{0 . 8 4 4}$ \\
Y22 & 0.453 & 0.686 & 0.445 & $\mathbf{0 . 9 2 4}$ \\
Y23 & 0.424 & 0.636 & 0.409 & $\mathbf{0 . 9 1 1}$ \\
Y24 & 0.362 & 0.470 & 0.281 & $\mathbf{0 . 7 6 7}$ \\
\hline
\end{tabular}

\subsubsection{Evaluasi model struktural}

1). Koefisien Determinasi

Tabel 9. Koefisien determinasi

\begin{tabular}{cc}
\hline Variabel Laten Endogen & Nilai $\boldsymbol{R}^{2}$ \\
\hline Kepuasan Konsumen & 0,670 \\
Loyalitas Konsumen & 0,478 \\
\hline
\end{tabular}

hal ini mengindikasikan bahwa variabel kepuasan konsumen dapat dijelaskan oleh variabel kualitas produk dan harga sebesar 67\%, sedangkan 33\% dijelaskan oleh variabel lain di luar penelitian. Kemudian, variabel loyalitas konsumen dapat dijelaskan oleh variabel kepuasan konsumen sebesar 47,8\%, sedangkan 52,2\% dipengaruhi oleh faktor lain.

2). Predictive Relevance $\left(\mathrm{Q}^{2}\right)$

\begin{tabular}{cc} 
Tabel 10. Nilai Predictive Relevance $\left(\mathrm{Q}^{2}\right)$ \\
\hline Variabel Laten Endogen & Nilai $\boldsymbol{Q}^{2}$ \\
\hline Kepuasan Konsumen $\left(\eta_{1}\right)$ & 0,518 \\
Loyalitas Konsumen $\left(\eta_{2}\right)$ & 0,351 \\
\hline
\end{tabular}

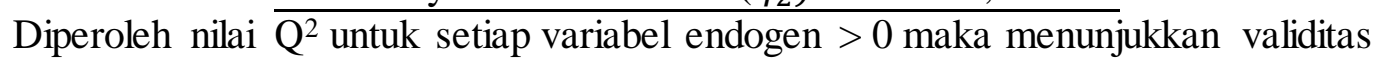
prediktif yang baik.

3). Model Fit

Tabel 11. Model Fit

\begin{tabular}{lccc}
\hline \multicolumn{1}{c}{ Model Fit } & Krite ria & Hasil Analisis & Ke te rangan \\
\hline SRMR (Standardized Root & SRMR $<0,1$ & 0,088 & Baik \\
Mean Square Residual) & $0<\mathrm{NFI}<1$ & 0,768 & Baik \\
NFI (Normed Fit Index) & $0<$
\end{tabular}

Berdasarkan hasil output disimpulkan bahwa model sudah baik. hal ini mengindikas ikan bahwa estimasi model sudah cocok dengan data yang telah diobservasi.

\subsubsection{Pembahasan Model}

Model pengukuran untuk variabel Kualitas Produk:

$$
\begin{array}{ll}
\mathrm{X}_{11}=0,604 \xi_{1}+\delta_{11} & \mathrm{X}_{14}=0,688 \xi_{1}+\delta_{14} \\
\mathrm{X}_{12}=0,849 \xi_{1}+\delta_{12} & \mathrm{X}_{15}=0,853 \xi_{1}+\delta_{15} \\
\mathrm{X}_{13}=0,874 \xi_{1}+\delta_{13} &
\end{array}
$$


Model pengukuran untuk variabel Harga:

$$
\begin{array}{ll}
X_{21}=0,887 \xi_{2}+\delta_{21} & X_{23}=0,854 \xi_{2}+\delta_{23} \\
X_{22}=0,832 \xi_{2}+\delta_{22} & X_{24}=0,880 \xi_{2}+\delta_{24}
\end{array}
$$

Model pengukuran untuk variabel Kepuasan Konsumen:

$$
\begin{array}{ll}
\mathrm{Y}_{11}=0,874 \eta_{1}+\varepsilon_{11} & \mathrm{Y}_{14}=0,928 \eta_{1}+\varepsilon_{14} \\
\mathrm{Y}_{12}=0,879 \eta_{1}+\varepsilon_{12} & \mathrm{Y}_{15}=0,867 \eta_{1}+\varepsilon_{15} \\
\mathrm{Y}_{13}=0,894 \eta_{1}+\varepsilon_{13} &
\end{array}
$$

Model pengukuran untuk variabel Loyalitas Konsumen:

$$
\begin{array}{ll}
\mathrm{Y}_{11}=0,844 \eta_{2}+\varepsilon_{11} & \mathrm{Y}_{14}=0,767 \eta_{2}+\varepsilon_{14} \\
\mathrm{Y}_{12}=0,924 \eta_{2}+\varepsilon_{12} & \mathrm{Y}_{13}=0,911 \eta_{2}+\varepsilon_{13}
\end{array}
$$

Sedangkan, model struktural terbaik untuk variabel Kepuasan Konsumen adalah:

$$
\eta_{1}=0,519 \xi_{1}+0,428 \xi_{2}+\zeta_{1}
$$

dan, model struktural terbaik untuk variabel Loyalitas Konsumen adalah:

$$
\eta_{2}=0,344 \eta_{1}+\zeta_{2}
$$

\section{KESIMPULAN}

Berdasarkan hasil analisis data dan pembahasan, dapat disimpulkan bahwa 26 butir pernyataan kuisioner yang disebarkan kepada responden mampu digunakan untuk mengukur tiap-tiap variabel laten (Kualitas Produk, Harga, Citra merek, Promosi, Kepuasan Konsumen, dan Loyalitas Konsumen). Kualitas Produk dan Harga memiliki pengaruh terhadap Kepuasan Konsumen smartphone merek Samsung sebesar $67 \%$ dan $33 \%$ dipengaruhi oleh faktor lain. Sedangkan, Kepuasan Konsumen hanya memiliki pengaruh 47,8\% terhadap Loyalitas Konsumen smartphone merek Samsung, dan sisanya dipengaruhi oleh faktor lain. Artinya mahasiswa Universitas Diponegoro yang puas terhadap smartphone merek Samsung, belum tentu loyal terhadap smartphone merek Samsung.

\section{DAFTAR PUSTAKA}

Abdillah, W., \& Jogiyanto. 2015. PARTIAL LEAST SQUARE (PLS) Alternatif STRUKTURAL EQUATION MODELLING (SEM) dalam Penelitian Bisnis. Bengkulu: ANDI Yogyakarta.

Fitriani, V., \& Sharif, O. O. 2018. "Analisis Faktor yang mempengaruhi Loyalitas Merek Konsumen pada Produk Kosmetik." e-Proceeding of Management 5 (1), 90-95.

Gaol, A. L., Hidayat, K., dan Sunarti. 2012. "Pengaruh Kualitas Produk terhadap Tingkat Kepuasan Konsumen dan Loyalitas Konsumen.” Jurnal Administrasi Bisnis.

Ghozali, I. 2011. "Aplikasi Analisis Multivariate Dengan Program SPSS”. Semarang: Badan Penerbit Universitas Diponegoro.

Ghozali, I \& Latan, H. 2014. Partial Least Squares Konsep, Metode dan Aplikasi Menggunakan Program WarpPLS 4.0. Semarang: BP Universitas Diponegoro.

Gujarati, D. 1978. Ekonometrika Dasar. terjemahan oleh Sumarno Zain. Jakarta: Erlangga.

Hurriyati, R. 2005. Bauran Pemasaran dan Loyalitas Konsumen, Bandung: Alfabeta.

Natalia, E., Hoyyi, A. dan Santoso, R. 2017. "Analisis Kepuasan Masyarakat terhadap Pelayanan Publik Menggunakan Pendekatan Partial Least Square (PLS)." Jurnal Gaussian 313-323.

Ningsi, W. 2012. Pemodelan Ketahanan PAngan Indonesia dengan Menggunakan Partial Least Square Path Modelling (PLS-PM). Tesis. Institut Pertanian Bogor.

Sondakh, C. 2014. "Kualitas Layanan, Citra Merek dan Pengaruhnya Terhadap Kepuasan Nasabah dan Loyalitas Nasabah Tabungan (Studi pada Nasabah Taplus BNI Cabang Manado)". Jurnal Riset Bisnis dan Manajemen, Vol 3 No. 1. Fakultas Ekonomi dan Bisnis Universitas Sam Ratulangi. 